\title{
Relationships between magical thinking, obsessive-compulsiveness and other forms of anxiety in a sample of non-clinical children
}

\author{
Laura M. Simonds, James D. Demetre \& Cristina Read
}

Despite the obvious phenomenological similarities between magical thinking and obsessive-compulsiveness, the relationship between them has been the subject of few empirical investigations in samples of children. The present study aimed to examine the relationship between a general epistemic stance towards magical causation and tendencies towards obsessive-compulsiveness in a non-clinical sample of schoolchildren. One-hundred and two children, aged between 5 and 10 years (48 boys, 54 girls), completed questionnaire measures designed to assess magical thinking, obsessive-compulsiveness and other forms of anxiety. School teachers completed a measure of strengths and difficulties for each child. General belief in magical causation was correlated with all types of anxiety, not just obsessive-compulsiveness, with significant correlations shown for boys in the sample, but not girls. General belief in magical causation contributed little to the prediction of obsessive-compulsiveness beyond general anxiety. In this study, a general epistemic stance towards magical causation did not differentiate obsessive-compulsiveness from other anxiety dimensions. The findings are considered in the context of developmental theories of magical and scientific causal reasoning. 
Magical thinking comprises the belief that 'one's thoughts, words, or actions can achieve specific physical effects in a manner not governed by the principles of ordinary transmission of energy or information' (Zusne \& Jones, 1989:13). In everyday contexts, seemingly 'magical' acts are employed in the face of threat or uncertainty, such as the enactment of rituals aimed at preventing individual and community harm (Frazer, 1959; Nemeroff \& Rozin, 2000; Subbotsky \& Quinteros, 2002), as well as common superstitious behaviours occasioned by anxiety, for example in competitive sport (Bleak \& Frederick, 1998; Burger \& Lynn, 2005) and when taking academic examinations (Gallagher \& Lewis, 2001). As Subbotsky (2004a) notes, adults have recourse to magical thinking to give an illusion of control in uncontrollable circumstances, thus giving a sense of hope. This suggests magical thinking coexists alongside more rational or scientific ways of reasoning and, as such, indicates a continuity of magical thinking from childhood to adulthood. Early in life, as Bolton (1996) observes, the enactment of rituals may provide children with a sense of control in the face of anxiety, fear or uncertainty. In support of this, it has been found that ritualistic behaviours are associated with stranger anxiety in children below the age of 4 years, and with a broader range of anxieties (contamination, death, violent crime) in older children (Evans, Gray \& Leckman, 1999). Furthermore, in early childhood, ritualistic behaviours are directly related to magical beliefs and explanations of phenomena, and inversely related to naturalistic or physical explanations of the same phenomena (Evans, Milanak, Madeiros \& Ross, 2002). Additionally, Piaget (1930) argued that the 'egocentric' preoperational child, typically below the age of 7 years, felt both guilt and fear when harbouring negative thoughts about others for fear that they might come true and the child would be responsible. 
The coexistence of scientific and magical ways of thinking would suggest that adults revert to magical ways of thinking to manage threat and uncertainty, processes that are part of 'normal' development and are not given up due to the inevitability of uncontrollable threat and uncertainty and the need to retain control, albeit illusory. Indeed, Piaget's observations concerning children's fears about the potential of negative thoughts to come true have parallels with the concept of 'thought-action fusion', a cognitive bias evident in adults with obsessive-compulsive disorder (OCD). The potential association between magical thinking and obsessive-compulsiveness has long been a concern for theorists and researchers, and has led some authors (e.g. Bolton et al., 2002) to observe that "the form of high anxiety and coping apparently most connected with magical thinking is obsessive-compulsion" (p482). Cognitive theorists have postulated that obsessive-compulsive cognition concerns a tendency to equate thoughts of having undertaken a harmful act with the actual act itself. One way in which this 'thought-action fusion' (TAF) manifests is in exaggerated probability estimates that bad thoughts can produce bad outcomes for self and/or others ('likelihood TAF'; Shafran, Thordarson \& Rachman, 1996). Theoretically, such thinking produces anxiety and attempts to nullify threat portended by an obsession and subsequent appraisal of it; that is, neutralising activity in the form of compulsions is provoked. While the topology of the relationship between obsession (e.g. fear of contamination) and neutralising (e.g. compulsive hand-washing) may have a logical link, frequently, the relationship appears arbitrary and without clear cause-effect relations. The tendency to engage in such arbitrary behaviours appears prima facie to be a manifestation of magical thinking: the 
person acts as if s/he believes that outcomes can be influenced by behaviours that, ontologically, have little or no causal bearing on the event in question. In the case of OCD it seems, therefore, that two points of what looks like magical thinking using Zusne and Jones' definition may be observed: one occurs at the onset of the thought (the belief that thinking of harm increases the likelihood of its occurrence), and the other occurs to manage the anxiety the aforementioned thought process provokes (if I count to ten, harm can be prevented). As Berle and Starcevic (2005) point out, likelihood TAF is similar to Piaget's notion of 'participation'. Given these observations, it might be predicted that likelihood TAF is positively associated with distress from obsessions and with neutralizing. Additionally, it might also be hypothesized that individuals with OCD hold more magical beliefs and more TAF beliefs than those without OCD. Experimental and correlational research offers some support for the hypothesized associations between likelihood TAF and obsessive-compulsive symptoms. Importantly, the developing evidence base does not support the specificity of TAF to OCD.

The reader is referred to Berle and Starcevic (2005) for a review of the TAF literature but some critical points are covered here in situating the current study. Some authors (e.g. Einstein and Menzies, 2004a, 2004b) suggest that likelihood TAF, along with superstitiousness, might be manifestations of a broader construct of magical ideation, basing this on the observation, in undergraduate and OCD patient samples, that whilst magical ideation was positively correlated with measures of obsessive-compulsiveness after controlling for TAF, when magical ideation was held constant, correlations between TAF and obsessive-compulsiveness were no longer 
significant. Einstein and Menzies conclude that obsessive-compulsiveness is associated with a general tendency toward magical thinking. Einstein and Menzies used the Magical Ideation Scale (Eckblad \& Chapman, 1983) which assesses a range of magical beliefs such as thought transmission, psychic phenomena and lucky charms and has been validated as a measure of schizotypy. In a further study, Einstein and Menzies (2006) found that OCD patients scored significantly higher in magical ideation than patients with Panic Disorder and non-anxious controls. The latter two groups did not differ significantly in magical ideation. This would suggest some specificity of magical ideation to OCD. Conversely, other research with adults and children questions the specificity of both TAF and magical ideation to obsessive-compulsiveness. For example, Barrett and Healey (2003) found that children with OCD had significantly higher TAF ratings than non-clinical children, but did not differ from children with other anxiety disorders. Similarly, studies involving adult OCD patients and those with other anxiety disorders question the specificity of TAF to OCD (e.g. Rassin, Diepstraten, Merckelback and Muris, 2001). Abramowitz, Whiteside, Lynam and Kalsy (2003) found that OCD patients differed significantly from patients with Social Phobia, but did not differ from patients with Generalised Anxiety Disorder, or those with Panic Disorder, on likelihood-TAF measures. Additionally, differences in TAF between OCD and other anxious patients seemed attributable to higher negative affect in the OCD group. Taken together, these studies suggest that TAF may be a cognitive bias evident across different anxiety disorders. Turning to magical ideation, in an experimental study using a TAF-induction paradigm, Bocci and Gordon (2007) found that, relative to non-neutralizers, spontaneous neutralizers scored significantly higher on a measure of 
magical ideation. Neutralizers and non-neutralizers did not differ, however, in obsessive-compulsiveness or trait anxiety suggesting the process may not be specific to obsessional problems. Hence, as with TAF, there seems to be mixed evidence concerning the specificity of magical ideation to obsessive-compulsiveness.

Currently, little empirical work has focused on the relationship between magical thinking and obsessive-compulsiveness and other types of anxiety in children. Given that the average OCD onset age is between 7.5 and 12.5 years (Geller, Biederman, Jones, Park, Schwartz, Shapiro \& Coffey, 1998) studies of these variables in childhood assume particular importance. Importantly, the emerging evidence base suggests that magical thinking might be relevant to a broad range of anxiety problems and, indeed, this would be a logical assertion given that magical thinking is proposed to be a strategy employed in the face of threat and uncertainty more broadly. In the first developmental study of magical thinking and obsessive-compulsiveness, Bolton, Dearsley, Madronal-Luque and Baron-Cohen (2002) devised a Magical Thinking Questionnaire to assess 5- to-17 -year-olds' beliefs in being able to make events happen through a thought or an action that was causally unrelated. For the sample as a whole, there were moderate correlations between magical thinking and obsessive-compulsiveness. Of considerable note, these authors also found that magical thinking was related to other types of anxiety, not just to obsessive-compulsiveness. Interestingly, and unexpectedly, this association was found for boys in the sample, but not girls. What is not clear from this study, however, is the extent to which the correlation between magical thinking and obsessive-compulsiveness is mediated by general anxiety.

The aim of the present study was to replicate and extend the work of Bolton et al. 
(2002) by providing further data on the association between magical thinking, obsessive-compulsiveness and anxiety in children, and by assessing the relationship between magical thinking and obsessive-compulsiveness whilst controlling for anxiety. The present study tested the claim that, in a sample of children, magical thinking is not a specific feature of obsessive-compulsive type thinking, but instead, that it is a factor contributing to various forms of anxiety. However, we were also interested in whether the gender differences in correlations between anxiety and magical thinking obtained by Bolton et al. (2002) would be observed, albeit in a sample with a narrower age range. Additionally, the study set out to examine whether magical thinking contributes unique variance to the prediction of obsessive-compulsiveness beyond that predicted by anxiety.

\section{Method}

\section{Participants}

Children $(n=102)$ from three infant/primary schools in South-East England took part. Although 116 children initially opted in, 14 were not included, either due to absence on data collection days $(n=11)$, psychiatric diagnosis (Asperger's Syndrome, $n=2)$ or special educational needs $(n=1)$. These latter three children were seen so that they did not feel excluded, but their data were not included in the analysis. One school served a diverse community with the largest groups of pupils from the United Kingdom, Africa and the Carribbean. The majority of children in the other two schools were from white British heritage. One of the three schools had a higher than national average number of 
children eligible for free school meals. The schools did not differ in proportion of children with special educational needs.

Of the 102 children included, there were 48 boys (47\%) and 54 girls ranging in age from 5 to 10 years (mean age 7.7 years, SD 1.7 years). The sample was divided into three school-year age groups: 5-6 year olds $(\mathrm{N}=33), 7-8$ year olds $(\mathrm{N}=27)$, and 9-10 year olds $(\mathrm{N}=34)$. A questionnaire was given out to the classroom teacher of every child that participated and 100 (98\%) were returned. No incentives were used to gain participation but each child received a small gift after taking part. Children and their parents/carers were aware of the general nature of the research but not of the specific hypotheses.

\section{Measures}

Short Leyton Obsessional Inventory - Child Version (SLOI-CV; Bamber, Tamplin, Park, Kyte \& Goodyer, 2002)

This is an 11-item self-report measure of obsessive-compulsive symptoms in children, present over the past two weeks. Scoring is a 4-point measure of symptom frequency (always $=3$, mostly $=2$, sometimes $=1$, and never $=0$ ) yielding a possible score range of 0 to 33 . Factor analysis $(n=253)$ reported by the scale authors indicated three subscales with satisfactory internal consistency: Compulsions $(\alpha=.73)$, Obsessions/incompleteness $(\alpha=.79)$, and Cleanliness $(\alpha=.75)$. The internal consistency of the full scale was high $(\alpha=.86)$. The full scale score was utilised in the current study. The SLOI-CV was originally validated with a sample of adolescents. Consequently, internal consistency analysis was conducted on SLOI-CV scores in the current study, with the sample divided 
into the school-year age groups. Results were as follows: 5-6 year age group, $\alpha=.76$ $(n=33) ; 7-8$ year age group, $\alpha=.65(n=27)$; and, 9-10 year age group, $\alpha=.79(n=34)$. The SLOI-CV, therefore, demonstrated adequate internal consistency in the current sample of children.

Magical Thinking Questionnaire (MTQ; Bolton et al., 2002)

This 30-item measure comprises two subscales, 'Thought' and 'Action', each consisting of 10 questions. Thought subscale questions ask whether it is possible to make some event happen just by thinking about it (e.g. 'Is it possible to move an object across a room just by thinking about it?') and is similar to the construct of TAF-likelihood. Action subscale questions ask whether it is possible by some action to make some event happen, the specified action being causally unrelated to the specified event (e.g. 'Is it possible to do really well at a test at school just by crossing your fingers?'). These two subscale scores sum to the MTQ total score. The remaining 10 questions, focussing on physical causal principles (e.g. 'Is it possible for snow to melt?'), assess bias for responding 'yes' or 'no'. Any respondent attaining a bias score of more than two should be excluded (D. Bolton, personal communication, 10 May 2005). The authors of the measure report a test-retest correlation for the MTQ total score of .90 $(n=17)$ in a sample of children and adolescents aged 5 to 17 years.

Spence Children's Anxiety Scale (SCAS; Spence, 1997)

This scale includes 38-items assessing six of the DSM-IV categories of anxiety disorder: separation anxiety, panic-agoraphobia, generalised anxiety, social phobia, fears of 
physical injury, and obsessive-compulsiveness. The subscales can be summed to give a total anxiety score. The chid is asked to rate, on a four point scale (never, sometimes, often or always), how often each item happens to them. The responses are scored 0-4 respectively, yielding a maximum possible score of 114. Six items assess obsessive-compulsive symptoms. The factor structure, reliability and validity of the scale have been supported in several previous studies of children and adolescents.

Strengths and Difficulties Questionnaire - Teacher Completed Version (SDQ; Goodman, 1997)

This is a brief behavioural screening questionnaire comprised of 25 attributes assessing conduct problems, hyperactivity, emotional symptoms, peer problems, and prosocial behaviour. Respondents use a 3-point Likert scale to indicate how far each attribute applies to the target child. All attributes except those related to prosocial behaviour are summed to generate a total difficulties score. The one-sided informant-rated version for teachers and parents of 4-16 year olds was used. Previous studies have supported the psychometric properties of the instrument (e.g. Goodman, 2001). In the current study, this measure was utilised to assess whether magical thinking was related to non-anxiety related problems in children.

\section{Ethical Considerations}

Written consent from parents/carers was required before a child could participate. The consent procedure gave parents/carers the option of requesting to be informed if their 
child appeared particularly worried or anxious during the study. The study took place in the school that participants attended. The author administering the questionnaires $(\mathrm{CR})$ remained sensitive to children's reactions during the procedure, and the potential for them getting upset. If it was felt the child presented as a clinical concern, the child's parent/carer would be invited for a face-to-face meeting with the researcher, but only if they had expressed a wish to be informed on the consent form. No child presented as a clinical concern.

\section{Procedure}

A pilot study was conducted with five children in the target age range. Four children could not understand the MTQ item 'Is it possible to lose a race just because you lost your lucky mascot or lucky charm?' Consequently, this item was excluded from the main study. In the study proper, a standard introduction was read to children prior to administration of the questionnaires, which were given in the following order: (1) MTQ, (2) SCAS, and (3) SLOI-CV. Following procedures reported by Bolton et al. (2002), younger children (5 and 6 year olds) were seen individually and the researcher read out the questionnaire items and hand-recorded children's responses. Older children ( 7 to 11 years olds) were seen in groups (of 3 or 4 in the current study) with the researcher

reading out the questions and each child recording their own answers. Administration time ranged from 30 to 50 minutes, depending on the child's age and ability. All children were given a short break between the second and third questionnaire. Additional breaks were given when necessary dependent on how the researcher gauged 
the child's attention. Upon completion of the task, each child was given time to ask questions and was given a gel pen.

\section{Results}

All data except for the SDQ scales appeared approximately normal from graphical output and Kolmogorov-Smirnov analyses. With the exception of the SDQ scales, the data were sufficiently normally distributed to be analysed using parametric statistical tests. Two-tailed tests were used throughout.

\section{Relationship between magical thinking and obsessive-compulsiveness}

As would be expected, the Pearson's correlation between the SLOI-CV and the SCAS obsessive-compulsive subscale indicated a significant positive correlation of a large effect size $(\mathrm{r}=0.61, \mathrm{n}=102, \mathrm{p}<0.001)$. Eight children scored more than two on the MTQ bias subscale and were subsequently excluded from further analyses involving the MTQ. Pearson's correlation coefficients were calculated between MTQ scores and scores on both the Short Leyton Obsessive-Compulsive Inventory (SLOI-CV) and the Spence Obsessive-Compulsive subscale (SCAS-OC) for the whole sample and for boys and girls separately. The results are shown in Table 1.

\section{INSERT TABLE 1 ABOUT HERE}

The prediction that magical thinking would be positively correlated with 
obsessive-compulsiveness was confirmed. Larger effect sizes were evident for the SLOI-CV. Analysis of the data divided by gender, however, indicates non-significant correlations between the SCAS-OC and MTQ scales for girls. The correlation between the MTQ-Thought scale and the SLOI-CV fails to reach significance in the sample of girls. Comparison of the coefficients using Fisher's transformation (Clark-Carter, 1997) indicated the correlations for boys were significantly greater $(\mathrm{p}<.05)$ than the girls for the MTQ Total and Thought subscale for both obsessive-compulsive measures. Correlations for the MTQ Action subscale did not differ significantly.

\section{Relationship between magical thinking and other forms of anxiety}

Pearson's correlation coefficients were calculated to examine the relationships between the MTQ total and subscales and the SCAS subscales assessing panic/agoraphobia, separation anxiety, social phobia, generalised anxiety, and physical injury fears. The results are shown in Table 2, for the whole sample and for boys and girls separately.

\section{INSERT TABLE 2 ABOUT HERE}

The prediction that there would be a positive relationship between magical thinking and other forms of anxiety was confirmed. When the data are assessed separately for boys and girls, however, the results indicate relationships of a moderate to large effect size for the boys on most subscales, except physical injury fears. Conversely, the correlations for girls are all small and statistically non-significant. Taken together with the findings shown previously in Table 1, consistent significant 
relationships between magical thinking and measures of obsessive-compulsiveness and other forms of anxiety were evident in the sample of boys, but not in the sample of girls.

Coefficients for boys and girls were again compared using Fisher's transformation. For MTQ Total, correlations for boys were significantly different $(\mathrm{p}<.05)$ from girls for Total Anxiety, Panic and Social Phobia. For MTQ Thought, correlations for boys were significantly different from girls for Total Anxiety $(\mathrm{p}<.05)$ and Social Phobia $(\mathrm{p}<.01)$. For MTQ Action, none of the correlations were significantly different ( $p>.05)$ between boys and girls.

\section{Does magical thinking contribute unique variance to obsessive-compulsiveness?}

Previous analyses indicated significant correlations between MTQ scales and the SLOI-CV and the SCAS-OC for boys. Furthermore, there were significant correlations between MTQ scales and other SCAS scales in the sample of boys. Conversely, relationships between MTQ scales and the SCAS-OC and other SCAS scales were generally small and non-significant for girls. Consequently, in assessing the contribution of magical thinking in predicting obsessive-compulsiveness, the analyses were conducted with data provided by boys only.

Regression analyses - male sample $(N=44)$

Hierarchical regression analysis was conducted with SLOI-CV scores as the criterion variable, with the SCAS Total Anxiety (minus the OC subscale) as the predictor entered on the first block and MTQ Total as the predictor entered on the second block. The model statistics are show in Table 3. 


\section{INSERT TABLE 3 ABOUT HERE}

Combined, SCAS Total Anxiety (excluding the OC subscale) and MTQ Total accounted for 59 per cent of the variability in SLOI-CV scores in boys; however, the MTQ failed to add significantly to the model as an individual predictor. A similar picture was evident when using the MTQ Thought and the MTQ Action scores in place of MTQ Total scores. Hierarchical regression analysis was then conducted with SCAS-OC scores as the criterion variable. The model statistics are show in Table 4.

\section{INSERT TABLE 4 ABOUT HERE}

A pattern similar to the SLOI-CV was found. Combined, the variables accounted for $54 \%$ of the variability in SCAS-OC scores but the MTQ failed to add significantly to the model as an individual predictor. A similar picture was evident when using the MTQ Thought and the MTQ Action scores in place of MTQ Total scores. MTQ scores did not contribute unique variance to the prediction of obsessive-compulsiveness beyond general anxiety.

\section{Supplementary Analyses}

It is possible that gender differences in correlations reflect the operation of other group differences between boys and girls. Consequently, independent t-tests were used to compare boys and girls in magical thinking, anxiety dimensions and age. Boys and girls 
did not differ significantly in MTQ Total, Thought or Action scores, or in any of the Spence Anxiety sub-scales, including the Obsessive-Compulsive subscale, or Total Anxiety. They did differ significantly in SLOI-CV scores: $t(92)=2.73, p=.007$. The mean score for girls was $12.08(\mathrm{SD}=5.94)$ and for boys it was 8.81 (5.55). Additionally, they also differed significantly in age: $t(92)=2.56, p=.012$. The mean age for girls was 8 years $(\mathrm{SD}=1.67)$ and for boys it was 7.15 years $(\mathrm{SD}=1.47)$. In light of the significant difference in age between boys and girls, correlations between the MTQ scales, SLOI-CV and SCAS scales were re-analysed by age-band. The results are shown in Table 5.

\section{INSERT TABLE 5 ABOUT HERE}

Correlations between the MTQ and the SLOI-CV suggest a pattern of age-related differences. However, correlations between the MTQ and the Spence Obsessive-Compulsive and other subscales, and Total Anxiety, do not reveal a clear pattern of age-related differences. The three age-groups did not differ significantly in MTQ Total scores: $F(2,91)<1$, n.s. For 5-6 year olds, the mean was 9.87 (SD 6.65), for 7-8 year olds it was 8.11 (SD 5.43), and for 9-10 year olds it was 7.97 (SD 6.34).

Finally, in order to examine whether magical thinking was related to other kinds of difficulties in children, scores on the Strengths and Difficulties Questionnaire (SDQ) were correlated with the MTQ. Spearman's rho was used as the SDQ data departed significantly from normality. The analysis revealed very small and non-significant relationships between the SDQ scales and the MTQ with coefficients ranging from .003 to .129 for the MTQ Total, from .006 to .107 for the MTQ Thought subscale, and from 
.083 to .129 for the MTQ Action subscale. It might have been expected that the SDQ emotional scale would have been related to magical thinking since it is similar to anxiety. However, the emotional scale did not correlate significantly with anxiety as measured by the SCAS full scale $(r h o=0.156, \mathrm{n}=100, \mathrm{p}>0.05)$.

\section{Discussion}

The findings of the present study indicated that magical thinking was moderately correlated with the two measures of obsessive-compulsiveness in children, and thereby broadly replicated the findings of Bolton et al. (2002). However, contrary to these investigators, significant correlations were found mainly for boys. Furthermore, correlation coefficients were significantly greater for boys than girls for the MTQ Total and Thought scales. Magical thinking was modestly to moderately correlated with each of the Spence Children's Anxiety subscales with significant correlations for boys, not girls, which replicated the findings of Bolton et al. (2002). Analyses further indicated that correlations between Total Anxiety and magical thinking were of comparable magnitude to the correlations between the two obsession-compulsion measures and magical thinking. Importantly, further analyses indicated magical thinking was not associated with other indices of emotional and behavioural difficulties as indexed by the Strength and Difficulties Questionnaire. Subsequent analyses in the sample of boys made use of an index of Total Anxiety (total SCAS excluding the Obsessive-Compulsive Subscale) to assess whether magical thinking added unique variance to the prediction of obsessive-compulsiveness beyond what was attributable to anxiety. This analysis revealed that a large and significant proportion of the variance in both measures of 
obsessive-compulsiveness could be attributed to Total Anxiety, with magical thinking accounting for very little additional variance.

The association between magical thinking and anxiety is consistent with findings that experimental manipulations that increase risk of loss of a prized possession also give rise to 'belief' in a magical outcome in adults and children (Subbotsky, 1997, 2001, 2004b). Magical thinking (at least as indexed by the MTQ) does not in turn appear to contribute to obsessive-compulsiveness. This may seem a surprising conclusion, given the affinity between the manifestations of obsessive-compulsiveness and magical thinking. This pattern of results suggests that magical thinking does not differentiate obsessive-compulsiveness from other anxiety dimensions. The findings are consistent with previous studies on magical ideation (e.g. Bocci \& Gordon, 2007) and likelihood TAF (e.g. Abramowitz et al., 2003; Barrett and Healy, 2003; and, Rassin et al., 2001) with these studies suggesting that magical ideation/TAF is not specific to obsessive-compulsiveness.

What is not clear at present is why the relationship between magical thinking and all types of anxiety should be present in boys, but not girls. In the present study there were group differences that may have contributed to gender differences in correlations. Girls scored significantly higher than boys on the SLOI-CV, although not on the SCAS-OC. It is possible that the reported gender differences in the relationship between magical thinking and obsessive-compulsiveness reflect a threshold effect; however, there were no gender differences in scores on the MTQ, which renders this possibility unlikely. Girls were also significantly older than boys, being approximately 10 months older on average. When correlations between magical thinking and 
obsessive-compulsiveness/other anxiety dimensions were calculated in the different age groups, the findings indicated that the relationship between obsession-compulsion and magical thinking was considerably stronger in the youngest group and may also explain, at least in part, why correlations for boys were higher than for girls. However, correlations between the MTQ and the Spence Obsessive-Compulsive and other subscales did not reveal such a clear pattern of age-related differences. These findings suggest that gender differences in the strength of correlations may not be explained by age differences between girls and boys in the present sample. Future studies should seek to disambiguate the influence of gender on correlations by matching girls and boys more closely on age and on the key variables indexed by the MTQ, SLOI-CV and the Spence Scales. At the same time, future studies might assess variables that could explain any observed gender differences in correlations. That is if, as evidenced in this study, boys and girls do not differ in magical thinking but that magical thinking is differentially related to anxiety in boys and girls (the latter finding also being observed by Bolton et al., 2002), this might suggest something about gender differences in anxiety management or in the phenomenology of anxiety. This raises the question of the function of magical thinking in boys and girls. A review of gender differences in locus of control by Sherman, Higgs and Williams (1997) suggests that this might be a fruitful variable to focus on in future research. These authors draw attention to findings that suggest gender differences in the perception of control over the uncontrollable, with males perceiving themselves as more capable than females. Additionally, these authors also indicate that the stress-distress relationship is mediated by internality for males, but not for females. Taken together, these findings might suggest that males may be more 
likely to have recourse to magical thinking to manage genuinely uncontrollable stressful events. As such, it could be the case that gender differences in correlations between magical thinking and anxiety might be attributable to gender differences in locus of control but future studies are needed to assess this possibility.

Both the present study, and the study by Bolton et al. (2002), found that children between 5 and 10 years of age produced quite high scores indicative of belief in magical causation. Moreover, neither study found an age-related decline in magical thinking scores. These findings are of considerable significance to conflicting models of the developmental relationship between magical thinking and scientific reasoning in children. Contrary to Piaget's “developmental replacement" model (Inhelder \& Piaget, 1958; Piaget, 1930), recent authors have attempted to make a conceptual and empirical case for the view that scientific reasoning does not inexorably replace magical causal attributions in development. Indeed, adherents of the "developmental coexistence" model maintain that the acts of imagination used in representing and reasoning about anomalous events show developmental continuity from early childhood to adolescence and even beyond (e.g. Johnson \& Harris, 1994; Subbotksy, 1992, 2004b). To date, experimental studies of the "developmental coexistence" hypothesis have produced ambiguous findings, perhaps due to using experimental events (e.g. Subbotsky, 1997) that might have a multitude of alternative explanations, and may not be an optimal context for assessing fundamental beliefs about magical causation. In contrast, the MTQ samples a broad range of anomalous phenomena and asks respondents to indicate whether or not they believe in the possibility of magical causation. The findings thus far generated with this instrument seem to be more closely in keeping with the developmental coexistence model. In this 
respect, Subbotsky (2001) argues cogently for the combination of behavioural and verbal indices in research. Subbotsky's work indicates that, in verbal expressions, a replacement model of causal thinking might be evident yet behavioural indices tend to support the coexistence model; children and adults might say they do not endorse magical beliefs but their behaviour might indicate otherwise. As such, both adults and children entertain the possibility of magical effects or, at the least, are not prepared to risk dispensing with such possibilities in situations involving threat. This leads on to a key conceptual issue: how is it possible to identify an instance of magical thinking? A behavioural measure (e.g. blowing on dice) may merely reflect dominant cultural practices, and perhaps more anxious individuals are more likely to resort to these. What is the actual belief underpinning this ritual? Such an act is akin to superstition and tells us nothing about the underlying epistemic state.

Any assessment of the findings would be incomplete without a discussion of methodological limitations of the study. The SLOI-CV has not been formally validated with children as young as 5 and 6 years. Although the internal consistency of the scale in the current study was adequate, future work is needed to validate the use of the scale in younger children. Additionally, a criticism that has been levelled at other non-clinical analogue research on obsessive-compulsiveness is that non-clinical phenomenology may not equate to clinical phenomenology. Therefore, future studies are needed that compare clinical and non-clinical groups on symptom measures and on correlations between them and anxiety and magical thinking. Notwithstanding this, the observation that magical thinking is associated with all types of anxiety, not just obsessive-compulsiveness, in a non-clinical sample is noteworthy if one considers a 
continuum notion of anxiety states. Validity and further reliability evidence is needed for the MTQ in samples of children and adolescents of different ages. Bolton et al. (2002) designed the MTQ to reflect mental and physical causation that is implied in definitions of magical thinking, for example that by Zusne and Jones (1989). The thinking subscale corresponds to TAF-likelihood. However, as Bolton et al. point out, scores in younger children might reflect immature causal reasoning and so could be tapping something different to that in older children. Additionally, the MTQ asks respondents to rate whether various effects are possible, rather than whether they themselves could be involved in producing such effects. As such, the current form might tap the domain of imagination rather than belief. As Berle and Starcevic (2005) point out, the literature contains varying conceptualisations of magical thinking. It is likely that, in using this concept, it is unclear whether the realm of thought, imagination or belief is being tapped. Previous research suggests that scores on the Magical Ideation Scale (MIS; Eckblad \& Chapman, 1983) might differentiate OCD patients from other anxious patients (e.g. Einstein \& Menzies, 2006). Items in the MIS are largely self-referent and it is this aspect that might lead to differentiation between OCD and other anxious groups, or that might differentially relate to obsessive-compulsiveness and to other anxiety problems in non-clinical samples. As the MIS is not validated for use in children, one possibility is that future studies might make use of a modified version of the MTQ that comprises self-referent items alongside the original version.

The current study raises some interesting speculations about the role of magical thinking in anxiety. Evidence appears to be accumulating that magical thinking, and its other manifestations such as TAF, may be an important feature across anxiety disorders. 
A general epistemic stance towards magical causation might be important in all disorders of anxiety, as it might be in varying expressions of non-pathological uncertainty, with the shape of that disorder (e.g. obsessionality, social anxiety) being determined by the content of the specific fears. In the case of obsessive-compulsiveness, O'Connor (2007) puts forward the idea that the obsessional reverts to 'primitive' states (i.e. compulsions) in order to manage his/her inability to tolerate negative affect, drawing attention to the focus in OCD of the person's ability to damage others. Ferrier and Brewin (2005) have found that OCD and anxious and non-anxious controls differ in their endorsement of 'dangerous self' traits with the OCD group endorsing these significantly more often than the other two groups. These authors speculate that a view of the self as dangerous may arise from early familial reactions to the expression of aggression. Notwithstanding the need for empirical verification of these speculations, interventions that focus on challenging the belief that one is dangerous, coupled with the development of alternative strategies for the management of emotion, might ameliorate recourse to the magical stance in OCD.

A significant limitation is that the current evidence is correlational and, as such, it is not possible to ascertain whether anxiety produces magical thinking, or vice versa, or whether the relationship between magical thinking and anxiety is the result of a third variable. Given this uncertainty, it can be observed that rituals are part of normal development and that, as O'Connor (2007) notes, the child has to develop a capacity for 'tolerating a world beyond magic' (p470). If magical thinking leads to anxiety, and magical thinking is acknowledged to be ubiquitous, then why is clinical anxiety relatively rare? Perhaps the more likely route is that anxiety prompts recourse to magical thinking 
and that, at times of high anxiety, and perceived low personal resources to cope, recourse to the magical stance might become more frequent and intractable. Future research is clearly needed that attempts to explicate the causal sequence, perhaps by utilising experimental manipulations of magical thinking and anxiety, ethical considerations notwithstanding. Additionally, longitudinal studies could usefully map the progression from normal childhood rituals to obsessive-compulsive concerns, and the presence and magnitude of anxiety and magical thinking at different time-points along this progression.

\section{Conclusion}

The findings of this study suggest that magical thinking does not differentiate obsessive-compulsiveness from other anxiety dimensions. Additionally, the current study indicates the existence of gender differences in the relationship between magical thinking and anxiety that require further exploration. Another important finding is that the relationship between anxiety and magical thinking held across the primary school age-range. An important implication of this is that developmental psychologists may need to go further in reconceptualising magical thinking in relation to anxieties and coping strategies across the life span. The prevailing view that magical thinking is merely a period-specific symptom of cognitive immaturity may not adequately account for the findings from the present study or other recent studies. Current limitations in the developing body of research on magical thinking and anxiety include the reliance on cross-sectional designs and conceptual issues in the definition of magical thinking and its measurement. Future studies should aim to focus on these issues. 


\section{References}

Abramowitz, J.S., Whiteside, S., Lynam, D. \& Kalsy, S. (2003). Is thought-action fusion specific to obsessive-compulsive disorder?: a mediating role of negative affect. Behaviour Research and Therapy, 41, 1069-1079.

Bamber, D., Tamplin, A., Park, R.J., Kyte, Z.A. \& Goodyer, I.M. (2002). Development of a short Leyton Obsessional Inventory for children and adolescents. Journal of the American Academy of Child and Adolescent Psychiatry, 41, 1246-1252.

Barrett, P.M. \& Healy, L.J. (2003). An examination of the cognitive processes involved in childhood obsessive-compulsive disorder. Behaviour Research and Therapy, 41, 285-299.

Berle, D. \& Starcevic, V. (2005). Thought-action fusion: Review of the literature and future directions. Clinical Psychology Review, 25, 263-284.

Bleak, J.L. \& Frederick, C.M. (1998). Superstitious behaviour in sport: levels of effectiveness and determinants of use in three collegiate sports. Journal of Sport Behaviour, 21, 1-15.

Bocci, L. \& Gordon, P.K. (2007). Does magical thinking produce neutralising behaviour? An experimental investigation. Behaviour Research and Therapy, 45, 1823-1833.

Bolton, D. (1996). Annotation: Developmental issues in obsessive-compulsive disorder. Journal of Child Psychology and Psychiatry, 37, 131-137.

Bolton, D., Dearsley, P., Madronal-Luque, R. \& Baron-Cohen, S. (2002). Magical thinking in childhood and adolescence: Development and relation to obsessive compulsion. British Journal of Developmental Psychology, 20, 479-494. 
Burger, J.M. \& Lynn, A.L. (2005). Superstitious behaviour among American and Japanese professional baseball players. Basic and Applied Social Psychology, 27, 71-76. Clark-Carter, D. (1997). Doing quantitative psychological research: from design to report. Hove: Psychology Press.

Eckblad, M. \& Chapman, L.J. (1983). Magical ideation as an indicator of schizotypy. Journal of Consulting and Clinical Psychology, 51, 215-225.

Einstein, D.A. \& Menzies, R.G. (2004a). Role of magical thinking in obsessive-compulsive symptoms in an undergraduate sample. Depression and Anxiety, 19, 174-179.

Einstein, D.A. \& Menzies, R.G. (2004b). The presence of magical thinking in obsessive compulsive disorder. Behaviour Research and Therapy, 42, 539-549.

Einstein, D.A. \& Menzies, R.G. (2006). Magical thinking in obsessive-compulsive disorder, panic disorder and the general community. Behavioural and Cognitive Psychotherapy, 34, 351-357.

Evans, D.W., Gray, F.L. \& Leckman, J.F. (1999). The rituals, fears and phobias of young children: insights from development, psychopathology and neurobiology. Child Psychiatry and Human Development, 29, 261-276.

Evans, D.W., Milanak, M.E., Medeiros, B. \& Ross, J.L. (2002). Magical beliefs and rituals in young children. Child Psychiatry and Human Development, 33, 43-58.

Ferrier, S. \& Brewin, C.R. (2005). Feared identity and obsessive-compulsive disorder. Behaviour Research and Therapy, 43, 1363-1374.

Frazer, J.G. (1959). The golden bough: A study in magic and religion. New York: Macmillan. (Originally published in 1890). 
Gallagher, T.J. \& Lewis, J.M. (2001). Rationalists, fatalists, and the modern superstitious: Test-taking in introductory sociology. Sociological Inquiry, 71, 1-12.

Geller, D., Biederman, J., Jones, J., Park, K., Schwartz, S., Shapiro, S. \& Coffey, B. (1998). Is juvenile obsessive-compulsive disorder a developmental subtype of the disorder? A review of the pediatric literature. Journal of the American Academy of Child and Adolescent Psychiatry, 37, 420-427.

Goodman, R. (1997). The Strengths and Difficulties Questionnaire: a research note. Journal of Child Psychology and Psychiatry, 38, 581-586.

Goodman, R. (2001). Psychometric properties of the Strengths and Difficulties Questionnaire (SDQ). Journal of the American Academy of Child and Adolescent Psychiatry, 40, 1337-1345.

Inhelder, B. \& Piaget, J. (1958). The growth of logical thinking from childhood to adolescence. New York: Basic Books

Johnson, C. \& Harris, P.L. (1994). Magic: Special but not excluded. British Journal of Developmental Psychology, 12, 35-52.

Nemeroff, C. \& Rozin, P. (2000). The makings of the magical mind: The nature and function of sympathetic magical thinking. In K.S. Rosengren, C.N. Johnson \& P.L. Harris (Eds.) Imagining the impossible: Magical, scientific and religious thinking in children. Cambridge: Cambridge University Press.

O'Connor, J. (2007). The dynamics of protection and exposure in the development of obsessive-compulsive disorder. Psychoanalytic Psychology, 24(3), 464-474.

Piaget, J. (1930). The child's conception of physical causality. Oxford: Harcourt Brace. Rassin, E., Diepstraten, P., Merckelbach, H. \& Muris, P. (2001). Thought-action fusion 
and thought suppression in obsessive-compulsive disorder. Behaviour Research and Therapy, 39, 757-764.

Shafran, R., Thordarson, D.S. \& Rachman, S. (1996). Thought action fusion in obsessive-compulsive disorder. Journal of Anxiety Disorders, 5, 379-391.

Sherman, A.C., Higgs, G.E. \& Williams, R.L. (1997). Gender differences in the locus of control construct. Psychology and Health, 12, 239-248.

Spence, S.H. (1997). Structure of anxiety symptoms among children: a confirmatory factor-analytic study. Journal of Abnormal Psychology, 106, 280-297.

Subbotksy, E. (1992). Foundations of the mind: Children's understanding of reality. London: Harvester-Wheatsheaf.

Subbotksy, E. (1997). Explanations of unusual events: Phenomenalistic causal judgements in children and adults. British Journal of Developmental Psychology, 15, 13-36.

Subbotsky, E. (2001). Causal explanations of events by children and adults: Can alternative causal models coexist in one mind? British Journal of Developmental Psychology, 19, 23-46.

Subbotsky, E. (2004a). Magical thinking - reality or illusion? The Psychologist, 17(6), 336-339.

Subbotsky, E. (2004b). Magical thinking in judgements of causation: Can anomalous phenomena affect ontological causal beliefs in children and adults? British Journal of Developmental Psychology, 22, 123-152.

Subbotsky, E.V. \& Quinteros, G. (2002). Do cultural factors affect causal beliefs: rational and magical thinking in Britain and Mexico. British Journal of Psychology, 93, 
519-543.

Zusne, L. \& Jones, W.H. (1989). Anomalistic psychology: A study of magical thinking (2nd ed.). Hillsdale, NJ: Erlbaum. 
Table 1: Pearson's correlations between MTQ, SLOI-CV and SCAS-OC scores

\begin{tabular}{|l|l|l|}
\hline & SLOI-CV & SCAS-OC \\
\hline MTQ Scale and group & & $.283^{* *}$ \\
\hline Total, All (N=94) & $.374 * * *$ & $.514 * * *$ \\
\hline Total, Boys (N=44) & $.550 * * *$ & .095 \\
\hline Total, Girls (N=50) & $.294 *$ & $.267 * *$ \\
\hline Thought, All (N=94) & $.348^{* * *}$ & $.494 * * *$ \\
\hline Thought, Boys (N=44) & $.532^{* * *}$ & .085 \\
\hline Thought, Girls (N=50) & .236 & $.233^{*}$ \\
\hline Action, All (N=94) & $.315^{* *}$ & $.382^{* *}$ \\
\hline Action, Boys (N=44) & $.406 * *$ & .093 \\
\hline Action, Girls (N=50) & $.333^{*}$ & \\
\hline
\end{tabular}

$* \mathrm{p}<.05 ; * * \mathrm{p}<.01 ; * * * \mathrm{p}<.001$ 
Table 2: Pearson correlations between MTQ and other SCAS subscale scores

\begin{tabular}{|c|c|c|c|c|c|c|}
\hline $\begin{array}{l}\text { MTQ Scale and } \\
\text { group }\end{array}$ & $\begin{array}{l}\text { SCAS- } \\
\text { Total }\end{array}$ & $\begin{array}{l}\text { SCAS- } \\
\text { Panic }\end{array}$ & $\begin{array}{l}\text { SCAS- } \\
\text { Separation }\end{array}$ & $\begin{array}{l}\text { SCAS- } \\
\text { Social }\end{array}$ & $\begin{array}{l}\text { SCAS- } \\
\text { General }\end{array}$ & $\begin{array}{l}\text { SCAS- } \\
\text { Injury }\end{array}$ \\
\hline $\begin{array}{l}\text { Total, All } \\
(\mathrm{N}=94)\end{array}$ & $.323 * *$ & $.297 * *$ & $.242 *$ & $.275^{* *}$ & $.270 * *$ & .201 \\
\hline $\begin{array}{l}\text { Total, Boys } \\
(\mathrm{N}=44)\end{array}$ & $.519 * * *$ & $.479 * * *$ & $.341 *$ & $.533 * * *$ & $.408 * *$ & .274 \\
\hline $\begin{array}{l}\text { Total, Girls } \\
(\mathrm{N}=50)\end{array}$ & .169 & .164 & .176 & .103 & .187 & .142 \\
\hline $\begin{array}{l}\text { Thought, All } \\
(\mathrm{N}=94)\end{array}$ & $.323 * *$ & $.261 *$ & $.221 *$ & $.264^{*}$ & $.233^{*}$ & $.235^{*}$ \\
\hline $\begin{array}{l}\text { Thought, Boys } \\
(\mathrm{N}=44)\end{array}$ & $.519 * * *$ & $.395 * *$ & $.340 *$ & $.520 * * *$ & $.343 *$ & $.327 *$ \\
\hline $\begin{array}{l}\text { Thought, Girls } \\
(\mathrm{N}=50)\end{array}$ & .169 & .157 & .131 & .080 & .154 & .159 \\
\hline $\begin{array}{l}\text { Action, All } \\
(\mathrm{N}=94)\end{array}$ & $.287 * *$ & $.273^{* *}$ & $.212 *$ & $.221 *$ & $.255^{*}$ & .098 \\
\hline $\begin{array}{l}\text { Action, Boys } \\
(\mathrm{N}=44)\end{array}$ & $.425^{* *}$ & $.439 * *$ & .238 & $.386^{*}$ & $.366^{*}$ & .124 \\
\hline $\begin{array}{l}\text { Action, Girls } \\
(\mathrm{N}=50)\end{array}$ & .194 & .143 & .219 & .121 & .205 & .087 \\
\hline
\end{tabular}

${ }^{*} \mathrm{p}<.05 ; * * \mathrm{p}<.01 ; * * * \mathrm{p}<.001$ 
Table 3: Model statistics for the prediction of SLOI-CV scores in boys

\begin{tabular}{|l|l|l|l|}
\hline & $B$ & SE B & $\beta$ \\
\hline Step 1 & 1.65 & 1.12 & \\
Constant & 0.28 & 0.04 & $.75^{*}$ \\
SCAS total (excl. OC) & & 1.17 & \\
\hline Step 2 & 0.89 & 0.04 & $.64^{*}$ \\
Constant & 0.24 & 0.11 & .22 \\
SCAS total (excl. OC) & 0.21 & \\
\hline MTQ total & & & \\
\hline
\end{tabular}

Note: $\mathrm{R}^{2}=.56(\mathrm{p}<.001)$ for Step $1 ; \Delta \mathrm{R}^{2}=.03(\mathrm{p}=.07)$ for Step $2 ;{ }^{*} \mathrm{p}<.001$

Table 4: Model statistics for the prediction of SCAS-OC scores in boys

\begin{tabular}{|l|l|l|l|}
\hline & $B$ & $S E B$ & $\beta$ \\
\hline Step 1 & 1.86 & 0.88 & \\
Constant & 0.20 & 0.03 & $.71^{*}$ \\
SCAS total (excl. OC) & 1.36 & 0.92 & \\
\hline Step 2 & 0.17 & 0.03 & $.61^{*}$ \\
SCAS total (excl. OC) & 0.14 & 0.09 & .19 \\
\hline MTQ total & & & \\
\hline
\end{tabular}

Note: $\mathrm{R}^{2}=.51(\mathrm{p}<.001)$ for Step $1 ; \Delta \mathrm{R}^{2}=.03(\mathrm{p}=.13)$ for Step $2 ;{ }^{*} \mathrm{p}<.001$ 
Table 5: Pearson's correlations between MTQ, SLOI-CV and SCAS scales by age-bands

\begin{tabular}{|l|c|c|c|}
\hline & $\begin{array}{c}5-6 \text { year olds } \\
(\mathrm{N}=33)\end{array}$ & $\begin{array}{c}7-8 \text { year olds } \\
(\mathrm{N}=27)\end{array}$ & $\begin{array}{c}9-11 \text { year olds } \\
(\mathrm{N}=34)\end{array}$ \\
\hline MTQ Total/SLOI-CV & $.63^{* *}$ & .23 & .17 \\
\hline MTQ Total/SCAS-OC & .34 & -.04 & $.35^{*}$ \\
\hline MTQ Total/SCAS Panic & .29 & $.44^{*}$ & .22 \\
\hline MTQ Total/SCAS Separation & .30 & .06 & $.34^{*}$ \\
\hline MTQ Total/SCAS Generalised & $.36^{*}$ & .25 & $.35^{*}$ \\
\hline MTQ Total/SCAS Total & $.42^{*}$ & $.73^{* *}$ & \\
\hline
\end{tabular}

$* \mathrm{p}<.05 ; * * \mathrm{p}<.01$ 